\title{
Sistemas de coberturas de solo no inverno e seus efeitos sobre o rendimento de grãos do milho em sucessão
}

\author{
Soil covering systems in the winter and its effects on maize grain yield grown in succession
}

\author{
Adriano Alves da Silva ${ }^{\mathrm{I}}$ Paulo Regis Ferreira da Silva ${ }^{\mathrm{I}}$ Elias Suhre ${ }^{\mathrm{II}}$ Gilber Argenta ${ }^{\mathrm{II}}$ \\ Mércio Luiz Strieder ${ }^{\mathrm{I}}$ Lisandro Rambo ${ }^{\mathrm{III}}$
}

\section{RESUMO}

O uso de aveia preta (Avena strigosa) como espécie de cobertura de solo no inverno causa imobilização do nitrogênio $(N)$, que reduz o desenvolvimento da planta e o rendimento de grãos de milho cultivados em sucessão. Desta forma, o consórcio de aveia preta com espécies leguminosas como ervilhaca comum (Vicia sativa) e com brassicáceas, como nabo forrageiro (Raphanus sativus), visa a aumentar a disponibilidade de $N$ no sistema e o tempo de permanência de resíduos na superfície do solo. Foram conduzidos dois experimentos em Eldorado do Sul-RS, nas estações de crescimento 2001/2002 e 2002/2003. O primeiro experimento teve o objetivo de avaliar o efeito de três espécies de cobertura de solo no inverno, implantadas de forma isolada $e$ consorciadas, sobre o rendimento de grãos de milho em sucessão, com e sem aplicação de $N$ em cobertura. O segundo experimento, por sua vez, visava a determinar a proporção mais adequada de sementes de nabo forrageiro e de aveia preta em consórcio para maior benefício ao milho em sucessão, sob diferentes níveis de $N$ em cobertura. No primeiro experimento, os tratamentos constaram da aplicação de $150 \mathrm{~kg}$ ha ${ }^{-1}$ de $N$ no milho em cobertura, de uma testemunha sem aplicação deste nutriente e de sete sistemas com plantas de coberturas de solo no inverno. No segundo experimento, os tratamentos constaram da aplicação de dois níveis de $N$ (75 e $\left.150 \mathrm{~kg} \mathrm{ha}^{-1}\right)$ no milho, de uma testemunha sem aplicação de $\mathrm{N}$ em cobertura e de cinco sistemas de coberturas de solo no inverno. Nos sistemas consorciados, independentemente da proporção de sementes utilizada, o nabo forrageiro contribuiu com a maior parte do rendimento total de matéria seca. $O$ consórcio de ervilhaca comum ou de nabo forrageiro com aveia preta minimiza o efeito negativo desta espécie sobre o rendimento de grãos de milho em sucessão, especialmente em sistemas com menor disponibilidade de $\mathrm{N}$ e, mesmo sob alto nível de $N$, o rendimento de grãos de milho também aumenta quando em sucessão à ervilhaca.

Palavras-chave: Zea mays, aveia preta, ervilhaca comum, nabo forrageiro, nitrogênio, consórcio entre espécies.

\section{ABSTRACT}

The black oats use (Avena strigosa) as species of soil covering in the winter, cause immobilization of the nitrogen $(N)$, that reduces the plant development and grain yield of maize cultivated in succession. Thus, the black oat intercropped systems with leguminous as common vetch (Vicia sativa) and brassicas as oilseed radish (Raphanus sativus) is aimed at increasing nitrogen $(N)$ disponibility in the system and the permanence timing of its residues in the soil. Two experiments were carried out in the growth seasons of 2001/2002 and 2002/ 2003, in Rio Grande do Sul, Brazil. The first one was aimed at evaluating the effect of three winter species of soil covering, grown as a single culture and as intercropped crops on maize grain yield, with and without nitrogen side-dressed. The second one was aimed at determining the most adequate seed ratio of oilseed radish and black oat in intercropped systems, as soil covering crops in the winter preceding maize, under different nitrogen levels side-dressed. In Experiment I, treatments were composed by $N$ application of $180 \mathrm{~kg} \mathrm{ha}^{-1}$, a control without $N$ side-dressed and seven winter soil covering systems. In the Experiment II, treatments consisted of two levels of $N$ sidedressing application in maize, a control without $N$ side-dressed, and of three seed ratio of oilseed radish and black oat, as single and as intercropped crops and a control without crop in the winter. In all intercropped systems, independently of seed ratio used, the oilseed radish was mostly responsible for the yield of dry mass of the systems. The intercropped systems of common vetch or oilseed radish with black oat minimize the negative effect of oat on maize grain yield cultivated in succession in systems with low $N$ availability and, even with high $N$ supply, maize grain yield also increases when grown after common vetch.

Key words: Zea mays, black oat, common vetch, oilseed radish, nitrogen, intercropping species.

'Universidade Federal do Rio Grande do Sul (UFRGS), Porto Alegre, RS, Brasil. E-mail: paulo.silva@ufrgs.br. Autor para correspondência.

"Instituto Nacional de Colonização e Reforma Agrária (INCRA), Bela Vista, RR, Brasil.

IIISyngenta Seeds Ltda, Desenvolvimento de Produtos, Uberlândia, MG, Brasil. 


\section{INTRODUÇÃO}

A maioria dos produtores de grãos do Estado do Rio Grande do Sul adota o sistema de semeadura direta, em que não há revolvimento do solo no preparo da área. Para assegurar sua sustentabilidade, é fundamental sua associação a um sistema de rotação e sucessão de culturas diversificado, que produza adequada quantidade de resíduos culturais na superfície do solo. Entre as vantagens da utilização de sistemas apropriados de rotação e de sucessão de culturas, destacam-se a estabilidade de rendimento de grãos, a quebra de ciclo de pragas e moléstias, a diminuição da infestação de plantas daninhas, a alternância na forma de extração de nutrientes com uso de espécies com diferentes sistemas radiculares e a manutenção ou melhoria das condições físicas do solo (REGO, 1994). O milho, por suas características fisiológicas e pelo manejo que vem sendo adotado em grande parte das propriedades, pode ser muito beneficiado por um sistema adequado de rotação e sucessão de culturas.

O rendimento médio de grãos de milho é inferior a $3 \mathrm{Mg} \mathrm{ha}^{-1}$ no Estado do Rio Grande do Sul (CONAB, 2005). Este rendimento de grãos é baixo quando comparado a rendimentos de 15,0 e $15,9 \mathrm{Mg}$ ha $^{-1}$, obtidos em condições experimentais em Eldorado do Sul-RS e em Lages-SC, respectivamente (ARGENTA et al., 2003). As principais causas da baixa produtividade são a deficiência hídrica que se verifica em períodos críticos de desenvolvimento da cultura e o inadequado nível de manejo, como uso insuficiente de fertilizantes e de densidade de plantas. Com a evolução do sistema de semeadura direta, novas técnicas de manejo são exigidas para aumentar o rendimento de grãos de milho, sem elevar o custo de produção. Entre estas, está o uso de espécies de cobertura de solo no inverno com capacidade de fixação e/ou reciclagem de nutrientes e que confiram maior proteção ao solo.

Entre as espécies de cobertura de solo no inverno, a aveia preta é a mais cultivada no Sul do Brasil, antecedendo os cultivos, principalmente, de milho e soja, no verão. Seu intenso uso se deve ao alto rendimento de matéria seca, à facilidade de aquisição de sementes e de implantação, à rusticidade, à rapidez de formação de cobertura, à eficiente reciclagem de $\mathrm{N} \mathrm{e}$ do ciclo adequado. Por outro lado, devido à alta relação carbono:nitrogênio $(\mathrm{C} / \mathrm{N})$, a velocidade de liberação de $\mathrm{N}$ de seus resíduos é lenta. Apenas $40 \%$ do $\mathrm{N}$ contido na planta são disponibilizados nas primeiras quatro semanas após seu manejo (AMADO et al., 1999; AITA et al., 2001; AITA \& GIACOMINI, 2003).
Uma alternativa para aumentar a disponibilidade de $\mathrm{N}$ no solo seria o uso de espécies leguminosas como culturas antecessoras ao milho, por possuírem a capacidade de fixar o $\mathrm{N}_{2}$ atmosférico através da simbiose com bactérias específicas. A quantidade de $\mathrm{N}$ acumulada durante o ciclo de espécies leguminosas, como a ervilhaca comum (Vicia sativa), pode chegar a 220 kg ha-1 (MONEGAT, 1991). Cerca de $60 \%$ do N presente na matéria seca da parte aérea desta espécie são liberados durante os primeiros 30 dias após seu manejo (AMADO et al. 1999; AITA et al., 2001; AITA \& GIACOMINI, 2003). Isso permite reduzir o uso de fertilizantes nitrogenados industriais no milho cultivado em sucessão e, conseqüentemente, o custo de produção da lavoura e o risco de contaminação ambiental devido à lixiviação de nitrato.

Outra espécie que possui potencial para aumentar a disponibilidade de $\mathrm{N}$ no solo é o nabo forrageiro (Raphanus sativus). Por ser da família das brassicáceas, ele não possui a capacidade de fixar $\mathrm{N}_{2}$ atmosférico, porém tem alta capacidade de extrair $\mathrm{N}$ de camadas mais profundas do solo, podendo chegar a $220 \mathrm{~kg} \mathrm{ha}^{-1}$ de N reciclado (HEINZMANN, 1985). Outras vantagens de sua utilização são: desenvolvimento inicial da planta muito rápido, alto rendimento de matéria seca e ciclo curto, o que viabiliza a semeadura precoce do milho em sucessão (meses de agosto e setembro). Essa espécie apresenta maior velocidade inicial de acúmulo de matérias fresca e seca em relação à aveia preta e à ervilhaca comum (JUNIOR et al., 2004; DERPSCH et al., 1991).

A semeadura precoce de milho é importante em regiões ecoclimáticas do Estado do Rio Grande do Sul em que há grande probabilidade de ocorrência de deficiência hídrica entre novembro e fevereiro (FORSTHOFER et al., 2006; Reunião Técnica Anual de Pesquisa do Milho, 2005), o que coincide com o período mais crítico da cultura (entre o pendoamento e 30 dias após), quando o milho é semeado em outubro (MATZENAUER et al., 2002). Altos rendimentos de matéria seca da parte aérea de nabo forrageiro, variando de 4,7 a 5,4Mg ha-1 , têm sido obtidos com a semeadura realizada em maio-junho, em experimentos na Depressão Central do Estado do Rio Grande do Sul (FORSTHOFER et al., 2006). Assim como ocorre com as leguminosas, uma de suas grandes limitações é a baixa relação $\mathrm{C} / \mathrm{N}$ dos resíduos, que têm rápida taxa de decomposição. Além disso, se mal manejado, essa espécie pode tornar-se importante planta daninha para os cultivos subseqüentes.

Apesar das vantagens do uso de ervilhaca comum e nabo forrageiro como coberturas de solo no inverno, antecedendo o milho, é importante o 
desenvolvimento de práticas culturais que possibilitem maior tempo de permanência de seus resíduos na superfície do solo. As espécies de cobertura de solo no inverno, quando cultivadas em cultivos solteiros, apresentam vantagens e desvantagens para o milho em sucessão e para o sistema semeadura direta, tornando difícil a indicação de uma espécie que reúna somente aspectos desejáveis. O uso de sistemas consorciados com diferentes espécies pode propiciar a formação de uma quantidade de resíduos de coberturas de solo mais próxima da ideal, aumentando o rendimento de grãos de milho cultivado em sucessão e resultando em benefícios para o sistema semeadura direta. Os sistemas consorciados de gramíneas com espécies leguminosas ou brássicas podem propiciar eficiente cobertura vegetal no solo e maior fixação ou reciclagem de nutrientes, principalmente de $\mathrm{N}$.

Os objetivos da pesquisa foram: i) avaliar os efeitos da aveia preta, ervilhaca comum e do nabo forrageiro como coberturas de solo no inverno, implantadas de forma isolada e consorciadas, sobre o rendimento de grãos de milho cultivados em sucessão, com e sem aplicação de N em cobertura e ii) determinar a proporção mais adequada de densidade de semeadura de nabo forrageiro e aveia preta em sistemas consorciados como coberturas de solo no inverno para maior benefício do milho em sucessão, sob diferentes níveis de $\mathrm{N}$ em cobertura.

\section{MATERIAL E MÉTODOS}

Dois experimentos foram conduzidos na Estação Experimental Agronômica, da Universidade Federal do Rio Grande do Sul, localizada no município de Eldorado do Sul-RS, região ecoclimática da Depressão Central, cujas coordenadas geográficas são $30^{\circ} 05^{\prime} \mathrm{S}, 51^{\circ} 40^{\prime} \mathrm{W}$ e $46 \mathrm{~m}$ de altitude, nas estações de crescimento 2001/2002 e 2002/2003. O clima da região é classificado por Köppen como subtropical úmido (BERGAMASCHI et al., 2003). O solo da área experimental pertence à unidade de mapeamento São Jerônimo, sendo classificado como Argissolo Vermelho Distrófico típico (EMBRAPA, 1999). Os valores dos atributos físicos e químicos do solo, na média dos dois anos, são os seguintes: densidade: $1.500 \mathrm{~g} \mathrm{dm}^{-3}$; argila: $435 \mathrm{~g} \mathrm{dm}^{-3}$; pH (água): 5,1; índice SMP: 5,8; P: $11 \mathrm{mg}$ $\mathrm{dcm}^{-3}$; K: $186 \mathrm{mg} \mathrm{dcm}^{-3}$; matéria orgânica: $33 \mathrm{~g} \mathrm{dm}^{-3} \mathrm{e}$ CTC: $10,1 \mathrm{cmol}_{\mathrm{C}} \mathrm{dcm}^{-3}$, conforme metodologia descrita em TEDESCO et al. (1995).

No primeiro ano (Experimento I), os tratamentos constaram da aplicação de $150 \mathrm{~kg} \mathrm{ha}^{-1}$ de N em cobertura no milho, de uma testemunha sem aplicação deste nutriente em cobertura e de sete sistemas com espécies de coberturas de solo no inverno: aveia preta (100\%), ervilhaca comum (100\%) e nabo forrageiro (100\%) em cultivos isolados, os consórcios aveia (50\%) + ervilhaca (50\%), aveia (50\%) + nabo (50\%), ervilhaca (50\%) + nabo (50\%) e aveia $(34 \%)+$ ervilhaca $(33 \%)+$ nabo $(33 \%)$ e, como tratamento testemunha, o pousio invernal. A cultivar de milho reagente foi a Pioneer 32R21, híbrido simples, de ciclo precoce, da empresa "Pioneer Sementes Ltda". O delineamento experimental foi o de blocos casualizados, dispostos em fatorial 2 x 7, com quatro repetições. Na tabela 1 , os valores percentuais entre parênteses após as espécies referem-se às quantidades de 100,80 e $12 \mathrm{~kg} \mathrm{ha}^{-1}$ de sementes utilizadas nos cultivos isolados de aveia preta, ervilhaca comum e nabo forrageiro, respectivamente.

No segundo ano (Experimento II), os tratamentos constaram da aplicação de dois níveis de $\mathrm{N}$ em cobertura (75 e $150 \mathrm{~kg} \mathrm{ha}^{-1}$ ) no milho, de uma testemunha sem aplicação de $\mathrm{N}$ e de cinco sistemas com espécies de coberturas de solo no inverno: aveia preta (100\%) e nabo (100\%) em cultivos isolados, os consórcios aveia $(75 \%)+$ nabo $(25 \%)$, aveia $(50 \%)+$ nabo (50\%) e aveia (25\%) + nabo (75\%). Na figura 1 , os valores percentuais entre parênteses após as espécies referem-se às quantidades de 100 e $12 \mathrm{~kg} \mathrm{ha}^{-1} \mathrm{de}$ sementes nos cultivos solteiros, respectivamente, de aveia preta e nabo forrageiro. O delineamento experimental foi de blocos casualizados, dispostos em fatorial $5 \times 3$, com três repetições. A cultivar reagente de milho foi a "NB 6210", híbrido simples, de ciclo precoce, da empresa Syngenta Seeds Ltda.

As espécies de cobertura de inverno foram implantadas em maio de 2001 e em junho de 2002, em sistema de semeadura direta. Nos sistemas consorciados, elas foram semeadas na mesma linha. As sementes de ervilhaca comum foram inoculadas com o rizóbio específico. As espécies de cobertura de solo foram roladas com rolo-faca quando as plantas de aveia preta estavam no estádio de grãos leitosos.

O milho foi semeado nos dias 2 de outubro de 2001 e 14 de outubro de 2002, um dia após se fazer a rolagem das espécies de cobertura de solo. As densidades foram de $70.000 \mathrm{pl} \mathrm{ha}{ }^{-1}$, em todos os tratamentos do Experimento I, e de 50.000, 65.000 e $80.000 \mathrm{pl} \mathrm{ha}^{-1}$ no Experimento II, respectivamente nos níveis sem aplicação de $\mathrm{N}$ em cobertura e nos níveis de 75 e $150 \mathrm{~kg} \mathrm{ha}^{-1}$ de N aplicado em cobertura. Portanto, os tratamentos no Experimento II devem ser considerados como um sistema, pois há variação em dois fatores, nível de nitrogênio aplicado em cobertura e densidade de plantas. A adubação de semeadura foi realizada na linha, com $120 \mathrm{~kg} \mathrm{ha}^{-1}$ de $_{2} \mathrm{O}_{5}$ e $120 \mathrm{~kg} \mathrm{ha}^{-1} \mathrm{de}$ 
Tabela 1 - Rendimentos de matéria seca e nitrogênio $(\mathrm{N})$ acumulado na parte aérea de aveia preta, ervilhaca comum e nabo, em cultivos solteiros e consorciados, e rendimento de grãos de milho cultivado em sucessão, com e sem aplicação de $\mathrm{N}$ em cobertura (experimento 1). Eldorado do Sul-RS, 2001/2002.

\begin{tabular}{|c|c|c|c|c|c|c|c|}
\hline \multirow{2}{*}{$\begin{array}{l}\text { Sistemas de coberturas de } \\
\text { solo no inverno }\end{array}$} & \multicolumn{4}{|c|}{$\begin{array}{l}\text { Rendimento de matéria seca } \\
\qquad\left(\mathrm{Mg} \mathrm{ha}^{-1}\right)\end{array}$} & \multirow{2}{*}{$\begin{array}{c}\mathrm{N} \text { acumulado na parte aérea } \\
\text { das coberturas de solo } \\
\left(\mathrm{kg} \mathrm{ha}^{-1}\right)\end{array}$} & \multicolumn{2}{|c|}{$\begin{array}{l}\text { Rendimento de grãos de milho } \\
\left(\mathrm{Mg} \mathrm{ha}^{-1}\right)\end{array}$} \\
\hline & Aveia & Ervilhaca & Nabo & Total & & Sem $N$ & $\begin{array}{c}150 \\
\left(\mathrm{~kg} \mathrm{ha}^{-1} \text { de N)}\right.\end{array}$ \\
\hline Pousio & & & & & $--^{(2)}$ & $7,2 \mathrm{~B} \mathrm{ab}$ & $12,8 \mathrm{~A} \mathrm{~b}$ \\
\hline Aveia preta & 3,6 & - & - & 3,6 bc $^{(3)}$ & $50 \mathrm{~b}$ & $4,0 \mathrm{~B} \mathrm{c}$ & $12,6 \mathrm{~A} \mathrm{~b}$ \\
\hline Ervilhaca comum (100\%) & - & 2,9 & - & $2,9 \mathrm{c}$ & $68 \mathrm{ab}$ & $8,2 \mathrm{~B}$ a & $14,4 \mathrm{~A} \mathrm{a}$ \\
\hline Nabo forrageiro (100\%) & - & - & 5,9 & 5,9 a & 87 a & $7,9 \mathrm{~B} \mathrm{a}$ & $12,4 \mathrm{~A} \mathrm{~b}$ \\
\hline $\begin{array}{l}\text { Aveia preta }(50 \%)+ \\
\text { ervilhaca comum }(50 \%)\end{array}$ & $1,6 \mathrm{~A}$ & $1,5 \mathrm{~A}$ & - & $3,1 \mathrm{c}$ & $50 \mathrm{~b}$ & $5,5 \mathrm{~B} \mathrm{bc}$ & $12,2 \mathrm{~A} \mathrm{~b}$ \\
\hline $\begin{array}{l}\text { Aveia preta }(50 \%)+\text { nabo } \\
\text { forrageiro }(50 \%)\end{array}$ & $1,5 \mathrm{~B}$ & - & $3,2 \mathrm{~A}$ & $4,7 \mathrm{ab}$ & $47 \mathrm{~b}$ & $7,4 \mathrm{~B}$ ab & $12,9 \mathrm{~A} \mathrm{~b}$ \\
\hline $\begin{array}{l}\text { Ervilhaca comum (50\%) + } \\
\text { nabo forrageiro (50\%) }\end{array}$ & - & $0,3 \mathrm{~B}$ & $2,9 \mathrm{~A}$ & $3,2 \mathrm{c}$ & $50 \mathrm{~b}$ & 7,3 B ab & $12,0 \mathrm{~A} \mathrm{~b}$ \\
\hline $\begin{array}{l}\text { Aveia }(34 \%)+\text { ervilhaca } \\
(33 \%)+\text { nabo }(33 \%)\end{array}$ & $1,2 \mathrm{~B}$ & $0,7 \mathrm{~B}$ & $1,7 \mathrm{AB}$ & 3,6 bc & $51 \mathrm{~b}$ & $7,2 \mathrm{~B}$ ab & $12,7 \mathrm{~A} \mathrm{~b}$ \\
\hline
\end{tabular}

${ }^{(1)}$ Os valores percentuais entre parêntese referem-se às quantidades de 100 , 80 e $12 \mathrm{~kg} \mathrm{ha}^{-1}$ de sementes nos cultivos isolados de aveia preta, ervilhaca comum e nabo forrageiro, respectivamente. ${ }^{(2)}$ Não-avaliado. ${ }^{(3)}$ Médias seguidas pela mesma letra minúscula na coluna e maiúscula na linha não diferem significativamente entre si pelo teste de Duncan $(\mathrm{P}<0,05)$.

$\mathrm{K}_{2} \mathrm{O}$, respectivamente, na forma de superfosfato triplo $\left(42 \% \mathrm{P}_{2} \mathrm{O}_{5}\right)$ e de cloreto de potássio $\left(60 \% \mathrm{~K}_{2} \mathrm{O}\right)$. Em todos os tratamentos foram aplicados $30 \mathrm{~kg} \mathrm{ha}^{-1}$ de N na semeadura. No primeiro ano, a adubação nitrogenada em cobertura foi parcelada em três doses iguais aplicadas, respectivamente, nos estádios de três (V3), seis (V6) e de 10 (V10) folhas expandidas, conforme escala proposta por RITCHIE et al. (1993). No Experimento II, a adubação nitrogenada em cobertura foi parcelada em duas vezes, nos estádios V6 e V11. Nos dois experimentos, a fonte de $\mathrm{N}$ utilizada foi a uréia, aplicada manualmente na linha de semeadura.

Nos dois experimentos, a quantidade de água disponível no solo foi mantida próxima à capacidade de campo mediante suplementação hídrica. A irrigação por aspersão foi realizada quando o potencial de água no solo era inferior a-0,04 Mpa, com vazão de $10 \mathrm{~mm} \mathrm{~h}^{-1}$. Pragas e plantas daninhas foram controladas para não interferirem no rendimento de grãos de milho.

Nos dois anos da pesquisa, determinou-se o rendimento de grãos de milho, a $13 \%$ de umidade. Nas espécies de coberturas de solo avaliou-se, nesses dois anos, o rendimento de matéria seca e, apenas no primeiro ano, o $\mathrm{N}$ acumulado nos resíduos no dia do manejo com rolo-faca. Os dados obtidos no Experimento I foram submetidos à análise de variância pelo teste $\mathrm{F}$ $(\mathrm{P}<0,05)$, sendo as médias comparadas pelo teste Duncan $(\mathrm{P}<0,05)$. Os dados obtidos no Experimento II foram submetidos à análise de regressão.

\section{RESULTADOSE DISCUSSÃO}

\section{Experimento 1}

O rendimento de matéria seca da parte aérea das espécies de cobertura de solo variou de 2,9 $\mathrm{Mg} \mathrm{ha}^{-1}$, com ervilhaca comum em cultivo solteiro, a 5,9 $\mathrm{Mg} \mathrm{ha}^{-1}$, com nabo forrageiro em cultivo solteiro (Tabela 1). Nos sistemas consorciados, o nabo forrageiro foi a espécie dominante, com maior rendimento de matéria seca. No consórcio ervilhaca comum (50\%) + nabo forrageiro (50\%), o maior rendimento de matéria seca do nabo forrageiro em relação ao da ervilhaca comum evidencia que, nesta relação de densidades de semeadura, estas duas espécies não formam um sistema consorciado adequado. Já no consórcio entre aveia preta e nabo forrageiro, não houve redução do rendimento total de matéria seca em relação ao do nabo forrageiro em cultivo isolado, indicando bom potencial para utilização. Informações mais específicas sobre este sistema consorciado serão apresentadas e discutidas no Experimento II.

Ao se analisar o sistema consorciado aveia preta (50\%) e ervilhaca comum (50\%), constata-se um equilíbrio no rendimento de matéria seca das duas espécies, indicando também se tratar de um sistema consorciado adequado (Tabela 1). No entanto, a sua adoção implica a semeadura do milho em sucessão apenas a partir do final de setembro e início de outubro, para se maximizar o potencial de rendimento de matéria seca da ervilhaca comum. A semeadura do milho nesta 


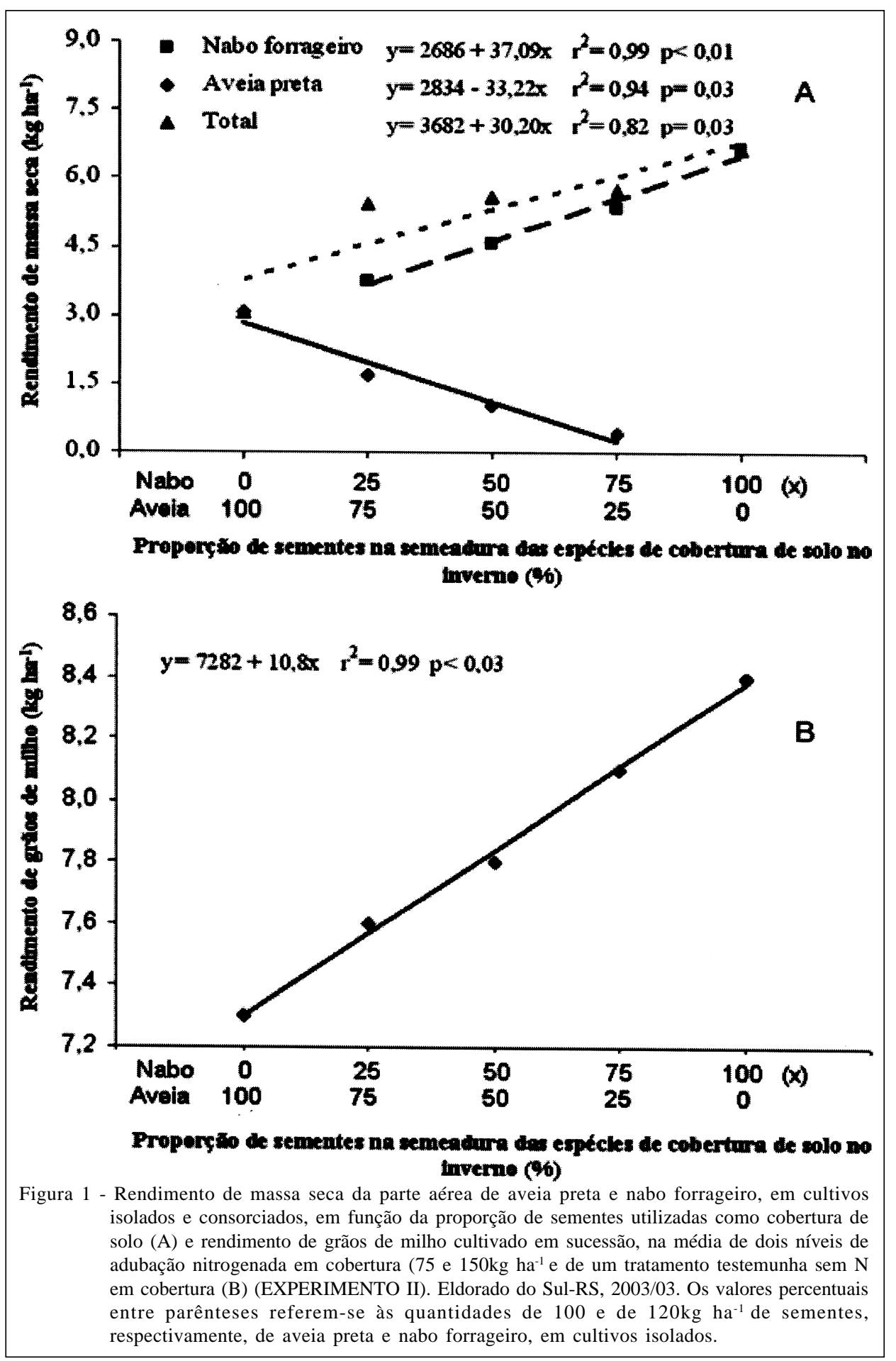

época, sob condições naturais de precipitação pluvial, faz com que o estádio de florescimento, que é o mais crítico à deficiência hídrica, coincida com o período do ano com maior probabilidade de deficiência hídrica no Estado do Rio Grande do Sul (MATZENAUER et al., 2002).
A maior quantidade de $\mathrm{N}$ acumulada na matéria seca da parte aérea das espécies de coberturas de solo, avaliada no dia da semeadura do milho, ocorreu no nabo forrageiro em cultivo isolado, o que pode ser atribuído em grande parte ao seu elevado rendimento de matéria seca (Tabela 1). Este valor foi similar ao obtido 
com o cultivo isolado de ervilhaca comum, confirmando os benefícios das altas capacidades de reciclagem de $\mathrm{N}$ do nabo forrageiro e de fixação biológica da ervilhaca comum.

O rendimento de grãos de milho variou de 4,0 $\mathrm{Mg} \mathrm{ha}^{-1}$, em sucessão à aveia preta em cultivo isolado sem aplicação de $\mathrm{N}$ em cobertura, a $14,4 \mathrm{Mg} \mathrm{ha}^{-1}$, em sucessão à ervilhaca comum em cultivo isolado, com aplicação de $150 \mathrm{~kg} \mathrm{ha}^{-1}$ de $\mathrm{N}$ em cobertura. Sem aplicação de $\mathrm{N}$ em cobertura, o rendimento de grãos de milho em sucessão aos cultivos isolados de ervilhaca comum e ao nabo forrageiro foram similares aos obtidos nos sistemas consorciados, exceto ao do consórcio aveia preta (50\%) e ervilhaca (50\%) e ao do tratamento pousio. Os rendimentos de grãos de milho obtidos sem aplicação de $\mathrm{N}$ em cobertura em sucessão aos cultivos isolados de ervilhaca comum e nabo forrageiro foram 105 e 97\% superiores em relação ao seu cultivo em sucessão à aveia preta, evidenciando os benefícios do uso dessas espécies e os prejuízos causados pela aveia preta sobre o milho cultivado em sucessão. Uma possível causa desta drástica redução do rendimento de grãos em sucessão à aveia preta pode ser a semeadura do milho ter sido feita apenas um dia após o seu manejo.

Nos tratamentos com aplicação de $180 \mathrm{~kg} \mathrm{ha}^{-1}$ de $\mathrm{N}$ em cobertura, o rendimento de grãos de milho também foi maior quando em sucessão ao cultivo solteiro de ervilhaca comum (14,4Mg ha-1), em relação aos demais sistemas, comprovando os benefícios desta leguminosa como cultura antecessora, mesmo com aplicação de altos níveis de $\mathrm{N}$ em cobertura no milho. Segundo BORKERT et al. (2003), cada tonelada de matéria seca de ervilhaca comum pode contribuir com $47 \mathrm{~kg}$ de N para o sistema solo-planta. Diferentemente dos resultados obtidos, DA ROS \& AITA (1996) verificaram que o rendimento de grãos de milho semeado em sucessão à ervilhaca comum não respondeu à adubação nitrogenada em cobertura. Este fato pode ser atribuído ao menor teto de produtividade obtido neste experimento. Segundo AITA \& GIACOMINI (2003), o cultivo da ervilhaca solteira libera maior parte do $\mathrm{N}$ durante os primeiros quinze dias de decomposição de seus resíduos. Ao final do primeiro mês após colocação de bolsas de decomposição no campo, havia apenas 57\% de resíduos remanescentes. Outros estudos também demonstram a rápida decomposição de resíduos de leguminosas (RANELLS \& WAGGER, 1992; DA ROS, 1993).

\section{Experimento 2}

O rendimento de matéria seca total da parte aérea das coberturas de solo no inverno variou de
$3,6 \mathrm{Mg} \mathrm{ha}^{-1}$, no cultivo solteiro de aveia preta, a $6,7 \mathrm{Mg}$ $\mathrm{ha}^{-1}$, no cultivo solteiro de nabo forrageiro (Figura 1A), evidenciando o grande potencial de rendimento do nabo forrageiro no local de realização da pesquisa. Essa espécie dominou a aveia preta e foi a que mais contribuiu para o aumento no rendimento total de matéria seca nos cultivos consorciados. Mesmo no consórcio com predominância na semeadura de aveia preta (75\%), o rendimento total de matéria seca foi de $4,4 \mathrm{Mg} \mathrm{ha}{ }^{-1}$, do qual $70 \%$ foram devidos ao nabo forrageiro.

O rendimento de grãos de milho variou de $7,3 \mathrm{Mg} \mathrm{ha}^{-1}$, em sucessão à aveia preta em cultivo isolado, a 8,3Mg ha ${ }^{-1}$, em sucessão ao nabo forrageiro em cultivo isolado. Houve apenas efeito simples de proporção de sementes na semeadura das espécies de cobertura de solo, não havendo interação entre este fator e os níveis de $\mathrm{N}$ aplicado em cobertura. Na média dos dois níveis de $\mathrm{N}$ aplicado em cobertura e da testemunha sem $\mathrm{N}$ em cobertura, o rendimento de grãos de milho aumentou linearmente à medida que aumentou a proporção de nabo forrageiro no consórcio e diminuiu a de aveia preta (Figura 1B), evidenciando o aumento da disponibilidade de $\mathrm{N}$ pelo nabo forrageiro devido ao processo de reciclagem (AMADO, 1997).

Os elevados rendimentos de matéria seca na parte aérea nas espécies de inverno (nos dois experimentos) e de $\mathrm{N}$ acumulado na matéria seca (no primeiro ano) evidenciam o grande potencial do uso de sistemas consorciados de gramíneas com leguminosas ou com brássicas em relação ao cultivo isolado de aveia preta, como culturas antecessoras ao milho. Com essa estratégia de manejo, pode-se manter adequada quantidade de palha na superfície do solo, importante para a sustentabilidade do sistema semeadura direta, além de aumentar a disponibilidade de $\mathrm{N}$ para o milho em sucessão pelos processos de fixação biológica e de reciclagem. Esses dados confirmam os obtidos por BORTOLINI et al. (2000) de que o uso do consórcio de aveia preta com ervilhaca comum diminui a necessidade de adubação nitrogenada no milho em sucessão, sem reduzir o rendimento total de matéria seca nos sistemas de consórcio de espécies em relação ao cultivo isolado de aveia preta.

O baixo rendimento de grãos de milho em sucessão à aveia preta pode ser atribuído à alta relação $\mathrm{C} / \mathrm{N}$ de seus resíduos, que imobiliza boa parte do $\mathrm{N}$ do solo pela ação dos microorganismos que atuam na decomposição dos resíduos de aveia, reduzindo a disponibilidade de $\mathrm{N}$ no solo e, conseqüentemente, para o milho (VICTORIA et al., 1992; VARGAS et al., 2005). Outro fator importante que determina menor rendimento de grãos de milho em sucessão à aveia 
preta em relação à ervilhaca comum é a baixa taxa de liberação de $\mathrm{N}$, pois apenas $40 \%$ do $\mathrm{N}$ contido nos resíduos são disponibilizados nas primeiras quatro semanas após seu manejo (AMADO et al., 1999; AITA et al., 2001; AITAE GIACOMINI, 2003), resultando em assincronia entre a liberação e as necessidades de $\mathrm{N}$ da planta de milho.

Outro aspecto desfavorável da sucessão de espécies da mesma família, como milho e aveia preta, e que tem sido pouco considerado pelos produtores, é a maior probabilidade de incidência de doenças comuns às duas espécies, principalmente em situações de estresse à planta, como por baixa disponibilidade de $\mathrm{N}$ (CASA \& REIS, 2003). A ocorrência de patógenos foliares, associada a deficiências nutricionais, são fatores que estimulam a senescência foliar prematura, restringindo a atividade fotossintética das plantas e seu potencial produtivo (NOODEN et al., 1997).

\section{CONCLUSÕES}

Sob baixa disponibilidade de $\mathrm{N}$ no solo para cultura do milho, as consorciações de uma gramínea com uma espécie das famílias das leguminosas ou das brássicas no inverno, de uma forma geral, aumentam o rendimento de grãos de milho em relação à sucessão à aveia preta em cultivo isolado, sem reduzir a quantidade de resíduos culturais no sistema semeadura direta. Por outro lado, sob alta disponibilidade de $\mathrm{N}$ no solo para cultura do milho, os efeitos das espécies de cobertura de solo no inverno, seja em cultivo isolado ou em consórcios, sobre o milho cultivado em sucessão, são similares, exceto quando em sucessão à ervilhaca comum, quando o milho apresenta maior rendimento.

Em todos os sistemas consorciados, independentemente da proporção de sementes utilizada, o nabo forrageiro foi a espécie dominante, contribuindo com maior parte do rendimento total de matéria seca da parte aérea das espécies de cobertura de solo. Nos sistemas consorciados entre aveia preta e nabo forrageiro, o rendimento de grãos de milho cultivado em sucessão é maior à medida que aumenta a proporção de nabo forrageiro no consórcio, independentemente da dose de $\mathrm{N}$ aplicada em cobertura.

\section{AGRADECIMENTOS}

Ao CNPq, pelas bolsas prêmio e de produtividade de pesquisa do segundo autor e pelas bolsas de pós-graduação e de iniciação científica dos estudantes participantes.

\section{REFERÊNCIAS}

AITA, C. et al. Plantas de cobertura de solo como fonte de nitrogênio ao milho. Revista Brasileira de Ciência do Solo, v.25, n.1, p.157-165, 2001.
AITA, C.; GIACOMINI, S.J. Decomposição e liberação de nitrogênio de resíduos culturais de plantas de cobertura de solo solteiras e consorciadas. Revista Brasileira de Ciência do Solo, v.27, n.3, p.601-612, 2003.

AMADO, T.J.C. Disponibilidade de nitrogênio para o milho em sistemas de cultura e preparo do solo. 1997. 201f. Tese (Doutorado em Ciência do Solo) - Universidade Federal do Rio Grande do Sul, Porto Alegre.

AMADO, T.J.C. et al. Culturas de cobertura, acúmulo de nitrogênio total no solo e produtividade de milho. Revista Brasileira de Ciência do Solo, v.23, n.3, p.679-686, 1999.

ARGENTA, G. et al. Potencial de rendimento de grãos de milho em dois ambientes e cinco sistemas de produção. Scientia Agraria, v.4, n.12, p.27-34, 2003.

BERGAMASCHI, H. et al. Clima da Estação Experimental da UFRGS (e região de abrangência). Porto Alegre: UFRGS, 2003. 77p.

BORKERT, C.M. et al. Nutrientes minerais na biomatéria da parte aérea em culturas de coberturas de solo. Pesquisa Agropecuária Brasileira, v.38, p.143-153, 2003.

BORTOLINI, C.G. et al. Sistemas consorciados de aveia preta e ervilhaca comum como cobertura de solo e seus efeitos na cultura do milho em sucessão. Revista Brasileira de Ciência do Solo, v.24, n.4, p.897-903, 2000.

CASA, R.T.; REIS, E.M. Doenças na cultura do milho In: ENCONTRO TÉCNICO DA CULTURA DO MILHO, 2003, Piracicaba, SP. Milho: estratégias de manejo para alta produtividade. Piracicaba: ESALQ/USP, 2003. V.4. p.1-18.

CONAB-Companhia Nacional de Abastecimento. Safra 2003/ 2004. Acesso em 05 jul. 2005. Online Disponível em www.conab.gov.br.

DA ROS, C.O. Plantas de inverno para cobertura do solo e fornecimento de nitrogênio ao milho em plantio direto. 1993. 85f. Dissertação (Mestrado em Ciência do Solo) Universidade Federal de Santa Maria, Santa Maria.

DERPSCH, R. et al. Controle da erosão no Paraná, Brasil: sistemas de cobertura do solo, plantio direto e preparo conservacionista do solo. Londrina: IAPAR, 1991. 272p.

DA ROS, C.O.; AITA, C. Efeito de espécies de inverno na cobertura do solo e fornecimento de nitrogênio ao milho em plantio direto. Revista Brasileira de Ciência do Solo, v.20, n.1, p.135-140, 1996.

EMBRAPA - Centro Nacional de Pesquisa de Solos. Sistema brasileiro de classificação de solos. Rio de Janeiro, 1999. 412p.

FORSTHOFER, E.L. et al. Desempenho agronômico e econômico do milho em diferentes níveis de manejo e épocas de semeadura. Pesquisa Agropecuária Brasileira, v.41, n.3, p.399-407, 2006.

HEINZMANN, F.X. Resíduos culturais de inverno e assimilação de nitrogênio por culturas de verão. Pesquisa Agropecuária Brasileira, v.20, n.9, p.1021-1030, 1985. 
JUNIOR, A.A.B. et al. Desempenho de plantas invernais na produção de matéria e cobertura do solo sob cultivos isolado e em consórcios. Revista de Ciências Agroveterinárias, v.3, n.1, p.38, 2004.

MATZENAUER, R. et al. Consumo de água e disponibilidade hídrica para milho e soja no Rio Grande do Sul. Porto Alegre: FEPAGRO, 2002. 105p. (Boletim FEPAGRO, 10)

MONEGAT, C. Plantas de cobertura de solo: características e manejo em pequenas propriedades. Chapecó: Ed. do Autor, 1991. 337p.

NOODEN, L.D. et al. Senescence mechanisms. Physiology Plantarum, v.101, n.3, p.746-753, 1997.

RANELLS, N.N.; WAGGER, M.G. Nitrogen release from crimson clover in relation to plant growth stage and composition. Agronomy Journal, v.84, p.424-430, 1992.

REGO, P.G. Economia das rotações de culturas em plantio direto. Revista Mensal Batavo. Fundação ABC, ed.31, p.2028, 1994.
Reunião Técnica Anual de Pesquisa de Milho e Sorgo do RS (50 e 33: 2005: Porto Alegre). Indicações técnicas para o cultivo de milho e sorgo no Rio Grande do Sul 2005/2006. Porto Alegre: FEPAGRO / Emater-RS / ASCAR, 2005. 155p.

RITCHIE, S.W. et al. How a corn plant develops? Ames: Iowa State University of Science and Technology. Cooperative Extension Service, 1993. (Special Report n.48).

TEDESCO, M.J. et al. Análise de solo, plantas e outros materiais. 2.ed. Porto Alegre: Departamento de Solos da UFRGS, 1995. 174p. (Boletim Técnico de Solos, 5).

VARGAS, L.K. et al. Imobilização de nitrogênio em solo cultivado com milho em sucessão à aveia preta nos sistemas plantio direto e convencional. Ciência Rural, v.35, p.76-83, 2005.

VICTORIA, R.L. et al. O ciclo do nitrogênio. In: CARDOSO, E.J.B.N. et al. (Coord). Microbiologia do solo. Campinas: Sociedade Brasileira de Ciência do Solo, 1992. p.105-119. 